\title{
Some procedural aspects of the introduction of predictive justice in the civil procedure
}

\author{
Konstantin L. Branovitskiy*, Vladimir V. Yarkov \\ Ural State Law University, Ekaterinburg, Russia
}

\begin{abstract}
Today the digitalization of justice is one of the defining development trends in most world legal order. The possibilities of filing lawsuits and petitions in electronic form, electronic mailboxes of lawyers, videoconferencing and online meetings have already firmly become the attributes of modern civil proceedings. This paper is devoted to further prospects for the digitalization of justice, namely, the analysis of the possibilities for the development and use of predictive justice. The paper presents the approach stating that this direction is one of the most suitable for the development of the civil process. Particular emphasis is placed on digitalization and pandemics as factors stimulating the development of predictive justice. It is emphasized that the scientific literature mainly discusses the ethical and philosophical aspects of using the possibilities of predictive justice in judicial proceedings. The authors justify the limits of the use of predictive justice based on the current concept of judicial power.
\end{abstract}

\section{Introduction}

Serious changes currently taking place in Russia and in the world in the social and economic life of society caused by the need to respond to new pandemic threats on the one hand, as well as the continued development of information technologies and, above all, artificial intelligence, on the other, are new challenges for the modern law and order in its traditional understanding. There is no doubt that the ability to confront such challenges as the global pandemic, both by individual states and by various integration associations, is a clear indication of the effectiveness and sustainability of the rule of law.

At the same time, it would not be absolutely true to consider that only COVID-19 pandemic factor itself is a call for the change of traditional ideas of such state institute as justice. Clearly, this factor played a great role in understanding the importance and, to some extent, the lack of alternative information technologies in judicial proceedings (due to quarantine measures, lockdown) in terms of guarantees of the availability of judicial protection of the rights and legitimate interests of citizens and organizations, and the openness of judicial proceedings. In turn, the possibility of participation of parties to a case in online sessions of the arbitral tribunal, or the existing features of the calculation of procedural deadlines in Austria or Germany, which appeared in the domestic legal order, were rather aimed at improving the guarantees of the right to be heard in court [1.pp. 40-42].

At the same time, the very process of serious transformation of the so-called "deritiualization" and "demateralization" of the process [2. pp. 3-6] began much earlier and was on the one hand a global trend and a change in perceptions of justice as a service, as well as the result of the active introduction of information technology in justice, on the other. In the latter case, the more the rule of law introduces modern technologies into the civil process, the earlier the need arises to understand the changes that are taking place as a result of this in the traditional view of the process as a certain ritual [3-5].

At the same time, there is a certain change in the current scientific agenda, namely, the general perception of digitalization as "improvement, acceleration and cheapening of the judicial process" is replaced by "privatization of justice", "competition with new dispute resolution mechanisms", "increased cost due to the need to maintain double infrastructure", etc. [6-9].

In this sense the transformation of justice that we are witnessing today is caused, first of all, by active implementation of digital technologies, the focus on which in domestic legal proceedings was taken long before the COVID-19 pandemic, which hit the whole world. The latter only added relevance to the transformational agenda.

\section{Research methods}

The methodology of research is formed by the general principles of scientific knowledge, approaches and methods traditionally related to the methodological apparatus of legal science and widely used in procedural legal scientific works, including dialectics, comparative legal method; the methods of formal legal analysis and legal design, etc.

*Corresponding author: branovitsky@ mail.ru 
In terms of the general characteristics of the methodological basis, the paper mainly deals with procedural and legal issues relevant to the substantive area of civil and arbitration proceedings in relation to domestic legislative regulation.

\section{Research results}

\section{Predictive justice as the next step in the development of the civil process}

One of the classic and uncontested postulates of the domestic procedural doctrine in the matter of court technology relations is that the large-scale introduction of digital technologies in judicial proceedings cannot and should not affect the essence of judicial activity, where decision-making should always remain with the judge. Modern technologies act exclusively as a means of solving the tasks of justice intrinsically playing a supporting role, i.e. exist at the initial stage of development [10. p. 214]. It can be safely argued that for the most part we are talking only about an instrumental approach to the use of technology and electronic communication in legal proceedings. The current objective focus on the digitalization of legal relations through the development of information technologies is reflected, in particular, in the Strategy for the Development of the Information Society in the Russian Federation for 2017-2030 [21].

The scientific literature reflects very cautious judgments about the weak prospects for the use of artificial intelligence in justice: "A human judge should use digital technologies as a legal assistant to carry out his activities... The ideal form of cooperation between a judge and artificial intelligence is seen in the instant processing of information and preparation of documentation by a robot, but the final decision is made by the judge" [11], primarily in view of the risks of intrusion of artificial intelligence into judicial discretion [11. p. 171]. The representatives of this approach note that to exclude the institution of judicial discretion means to deprive the proceedings of meaning.

Other researchers emphasize that regardless of the degree of automation of legal processes and the use of artificial intelligence in them, a person should have a direct impact on decisions [12. p. 118]. Besides, the opinion that the key problem of the use of artificial intelligence lies not in the field of technology, but in ethics, since the key question is not whether artificial intelligence possesses consciousness, but in the understanding that if, for example, we replace a human judge, then people will no longer be judged equal to themselves, seems quite interesting and noteworthy [13. p. 188].

On the other hand, there is an opposite opinion that the justice performed by artificial intelligence should be removed from the agenda in the very near future, since this is the only way to avoid judicial arbitrariness "as an inevitable component of human activity" [14].

Without delving into the discussion, we only note that in many ways such polar opinions arise when setting a provocative constellation, i.e. replacing a human judge with artificial intelligence, the key element is the concept of "replacement". It is the replacement of the judge with a "unit of artificial intelligence" that is one of the most debatable issues [15. p. 131].

At the same time, considering modern technologies in the paradigm of assisting the judge in the process of preparing, considering a civil case in the context of predictive justice [16], one can try to reduce the degree of discussion and, by considering the procedural features of such activities, get closer to its practical implementation.

First of all, let us dwell on the concept and substance of the phenomenon commonly called as the predictive justice. The doctrine notes that the current state of development of predictive justice is based on the analysis of judicial decision databases by algorithms. The algorithm learns to distinguish some factors characteristic of this group of disputes in court decisions. Besides, the analysis is carried out on the basis of language analysis.

Thus, today, such legaltech as "predictive justice" is a kind of "weak" artificial intelligence functioning on the basis of algorithms (a set of rules) created by people [17].

There is a need to indicate the current limits of its application in judicial proceedings as a fundamental issue in the analysis of predictive justice. Setting the limits is an essential element for the possible practical implementation of such legaltech in view of the following. If predictive justice is a kind/technology of artificial intelligence, then any "replacement" of a person with technology automatically throws us back to the discussion about the ethical aspects of artificial intelligence [17. p. 28] and at the same time distances from practical steps to introduce the legaltech in legal proceedings.

A possible way out of this situation could be the use of predictive justice as an auxiliary tool in the administration of justice while respecting one very important rule, namely the right to exercise all the possibilities of legaltech not only to the court, but also to the parties to the proceedings.

\section{Current approach}

Imagine a situation where only the court takes advantage of predictive justice as an auxiliary technology. In this case, with a properly configured and effective algorithm, only the court can get significant relief in work.

The parties to the proceedings in this case, on the contrary, may face a complication of the process, namely, the problems of "statistical truth", in which it will be more difficult to convince the judge of his position (different from the options proposed by the system).

The fact is that the average judge who does not use such legaltech is ready, in principle, to admit the existence of views and examples of judicial practice that are different from his own pre-formed conviction (for example, at the stage of preparing the case, studying 
written evidence), since he understands that he will not be able to know and monitor all changes in legislation, jurisprudence and doctrine. In such cases, the court's awareness of the "nature of the human judge" may enable the party to convince the judge of the correctness of the proposed approach and the erroneous preliminary assessment of the situation by the judge.

If the situation with the addition of a "weak" artificial intelligence in the form of predictive justice to the assistant judge changes, the preliminary conviction of the judge (the so-called subjective estimated result of consideration) will be multiplied by the statistical truth (the proposed result is considered based on the analysis of tens of thousands of similar cases), which the machine will offer. In this sense, we cannot exclude that subjective/judicial and "objective"/machine conviction may switch places over time and the judge, even before forming his position in the case, will "look up" the option proposed by the algorithm. In such a case, we may face some kind of the influence on the judge, which is unacceptable and violates the principle of independence. To illustrate a possible scenario, it is enough to imagine a situation from ordinary life in which the senior and much respected colleague of the judge in a private conversation "explained" his point of view on what is happening, on how to resolve a specific case before the latter studied the case.

In this case it will be more difficult for the parties to change the court's position only because they will be deprived of the opportunity to "see" the proposed legaltech decision of their case, understand and compare the actual circumstances of their case with how the algorithm understood them, etc.

In this case, we are faced not only with a possible violation of the principle of independence of judges, but also with the violation of the right to be heard. This right is inextricably linked to the idea of a state governed by the rule of law, in which everyone is guaranteed the right not only to act as the subject of legal proceedings, but also to speak out and influence the course of proceedings and its outcome, and the court is obliged to respect the rights of the parties to the proceedings [18]. It should be noted that there is no right to be heard as an independent principle in the Russian legal order. Reference to this principle as a general legal one ensuring respect for the right to a fair trial is contained in the decisions of the Constitutional Court of the Russian Federation No. 4-P of 12.03.2001, No. 17-P of 19.07.2011, No. 1-P of 19.01.2017.

This guarantee, known since the time of the Roman law as audiatur et altera pars, is manifested as three main elements in the German law [19]:

1) the right to receive information on the progress and content of proceedings, including the content of all petitions and statements of the opposite party and interim judicial acts;

2) the right to bring to court its position: the opportunity, at least in writing, to convey to the court both its point of view on the actual circumstances of the case and the legal position before the adoption of the final judicial act in the case;
3) the right to take into account this position by the court, which is considered in the context of the duty of the court to take into account and evaluate the position of the party in the case, including the motions and statements made by it.

In the case of such a law as the domestic law, when the court does not issue interim decisions (due to lack of relevant doctrine and legal regulation), does not explain its future decision to the parties (fearing accusations of impartiality), i.e. in the conditions of legal uncertainty maintained until the announcement of the decision, the addition of new uncertainty in the form of a solution hidden from the parties proposed by the algorithm is unlikely to increase the legal security of citizens and organizations, and meet the goals and objectives of the proceedings.

\section{Rationale for the study approach}

Considering the above-mentioned "peculiarities" of the domestic legal order, in the context of the application of the principles of legal certainty and ensuring the uniformity of judicial practice, we can try to move a little further than the mere advisory nature of predictive justice and make the proposed solution open to the participants in the proceedings.

The interests of the parties, and not only departmental tasks to reduce the burden on the courts, together with tasks to ensure the uniformity of judicial practice, could act as a catalyst for the practical implementation of the ideas of predictive justice in the domestic legal order.

Indeed, in a situation where one rule of law is applied differently, there is a threat of the unity of law and order in general. Uniformity in enforcement is the essence of justice achieved in a legal state through the principle of equality of all before the law. At the same time, the principle of equality of all before the law should connect all branches of government, including the judicial, although on a very limited scale, in connection with the presence of verification instances within the judicial system [20].

Such technology as predictive justice, which allows a judge automating the selection of judicial decisions to form his own legal position in resolving a case, can and should serve the interests not only of the court, but first of all of the parties. After all, the ultimate goal of justice is the protection and restoration of violated rights and legitimate interests.

Let us imagine the situation when following the results of the preparation of the case for trial, i.e. not only the judge, but also to the parties will be given the opportunity to familiarize themselves with the interim "decision on the basis of statistical data" following the analysis of the positions of the parties and presented evidence. In such a case, the court, while maintaining its independence, can and should continue to review the case and examine the evidence, while maintaining the possibility of making a final decision different from the proposed one. 
In turn, the parties may choose different lines of procedural conduct: from strengthening the winning position by providing additional evidence to refuting the proposed adjudication of a case, for example, due to differences in the actual composition of similar and pending cases, errors in a set of facts, etc. The possible increase in the attractiveness of conciliation procedures and settlement agreements in the face of increased predictability of the judicial act cannot be discounted.

Besides, the openness of the court to a dialogue and the possibility of expressing objections, as opposed to the closure of the results of predictive analysis, will contribute to increasing confidence in the judiciary in the eyes of society, the deficit of which, together with the certain closure of the court's dialogue with the participants in the proceedings (due to the multiple increase in written proceedings), is inherent in the domestic legal order.

\section{Conclusion}

The ongoing course towards the digitization of justice, the correctness of which was emphasized by the COVID-19 pandemic, leads to the inevitable transformation of the latter. In turn, the current procedural agenda began to play out in fresh colors in the conditions of the development of artificial intelligence. At the same time, most of the discussions around artificial intelligence in general and predictive justice focused on the admissibility/inadmissibility of replacing a person with a machine.

At the same time, it should be noted that both supporters and opponents of the need to introduce a robot judge unanimously speak of the impossibility of carrying out such a complete replacement to a greater extent for technological $\mathrm{f}$ and, to a lesser extent, ethical reasons.

In turn, when using the auxiliary functions of predictive justice (without replacing a person with a machine), the absence of serious technical problems of "weak" artificial intelligence is recognized, which undoubtedly requires further development and delicate adjustment. However, without taking into account procedural guarantees and the social nature of justice, without making this subsidiary process open, there is a serious risk that the discussion may remain "on paper" for a long time.

\section{Acknowledgments}

The paper was prepared and published as part of the grant of the Russian Foundation for Basic Research "Information Technologies and Jurisdictional Activities: Image of the Future of Justice" No. 18-29-16070".

\section{References}

1. K.L. Branovitskiy, I.G. Renz, V.V. Yarkov, Judicial legislation in the conditions of the coronavirus pandemic: nonsense or necessity? Law, 5, 40-42 (2020)

2. V.V. Yarkov, Principles of civil procedural law in the conditions of deritualization and dematerialization of justice, Arbitration and Civil Process, 11, 3-6 (2020)

3. T.Ya. Khabrieva, Law facing the challenges of digital reality, Journal of Russian law, 9, 5-17 (2018)

4. E.V. Talapina, Law and digitalization: new challenges and prospects, Journal of Russian Law, 2, 5-17 (2018)

5. P.V. Konstantinov, Digitalization as a modern threat to law, Bulletin of the civil process, 2, 149-156 (2019)

6. K.L. Branovitskiy, I.G. Renz, Al.V. Neznamov, An.V. Neznamov, V.V. Yarkov, Digital technologies in the civil process: some trends and prospects, Bulletin of the civil process, 4, 52-95 (2019)

7. A. Aliev, New methods of dispute resolution: competition and interaction with classical tools in the era of digitalization and globalization, Bulletin of the European-Asian Legal Congress, 1, 126-129 (2019)

8. M. Anosov, Digital technologies affect fundamental areas of law: what should lawyers prepare for in the near future? EG-Jurist, 9 (2018)

9. A.V. Neznamov, Digital education, access to justice and the economic component of digitalization of civil proceedings, Arbitration and civil proceedings, 9, 53-57 (2019)

10. S.V. Vasilkova, Electronic justice in the civil process: candidate dissertation (Petersburg, 2018)

11. K.E. Kovalenko, Yu.V. Pechatnova, D.A. Statsenko, N.E. Kovalenko, Robot judge as a way to overcome the contradictions of judicial discretion (legal aspects), DSU Legal Bulletin, 4, 169-173 (2020)

12. V.B. Nagrodskaya, New technologies (blockchain/artificial intelligence) in the service of law: scientific and methodological manual (ed. L.A. Novoselova) (Prospect, Moscow, 2019)

13. P. Bravo-Hurtado, Automation of the administration of justice: appeal to three erroneous judgments about artificial intelligence, Bulletin of the civil process, 1 (2018)

14. N.A. Kolokolov, Revisited artificial intelligence in justice, Criminal procedure, 4, 3-6 (2020)

15. P.M. Morhat, Legal personality of artificial intelligence in the field of intellectual property law: civil legal problems: doctoral dissertation (Moscow, 2018)

16. G.A. Vasilevich, Digitalization of law as a means of increasing its effectiveness, Constitutional and municipal law, 8, 32-35 (2019)

17. P.D. Konstantinov, Judicial discretion, template of court decisions and the nature of justice in the light 
of predictive justice, Arbitration and civil proceedings, 7, 27-31 (2020)

18. M.A. Fokina, Development of the adversarial principle in civil and arbitration proceedings, administrative proceedings by the Constitutional Court of the Russian Federation (to the $25^{\text {th }}$ anniversary of the Constitution of the Russian Federation); Modern law, 4, 72-83 (2019)

19. K.L. Branovitskiy, Concept and meaning of judicial guidance on the merits in German civil proceedings, Law, 4, 177-186 (2014)
20. K.L. Branovitskiy, I.G. Renz, V.V. Yarkov, Ensuring the unity of judicial practice in Russia and abroad: in search of balance, Law, 1, 69-84 (2020)

21. Strategy for the development of the information society in the Russian Federation for 2017-2030 (approved by the Decree of the President of the Russian Federation No. 203 of May 9, 2017); Corpus of Legislation of the Russian Federation, No. 20. Art. 2901 (2017) 